\title{
A Comparison of Pharmacy Dispensing Channel Use and Adherence to Specialty Drugs Among Medicare Part D Beneficiaries
}

\author{
Hrishikesh P. Kale, MS; Anisha M. Patel, PhD; and Norman V. Carroll, PhD
}

\begin{abstract}
BACKGROUND: Nonadherence to specialty drugs has been associated with poor clinical and economic outcomes. Studies conducted using commercial health plans suggest that patients who use specialty pharmacies have higher adherence compared with patients using retail pharmacies. However, little is known about the frequency of dispensing channel use or the association of dispensing channel use with adherence to specialty drugs among Medicare Part $D$ beneficiaries.
\end{abstract}

OBJECTIVES: To (a) describe the use of pharmacy dispensing channels by patients using self-administered specialty drugs in Medicare Part $D$ and (b) study the association between dispensing channel use and adherence to specialty drugs in this population.

METHODS: This study analyzed 2010 Medicare Part D data. Specialty drugs were defined as drugs with a mean cost $\geq \$ 600$ per month. We identified the top 13 specialty medications by cost and classified patients into the following classes: anticancer, disease-modifying therapy (DMT), and tumor necrosis factor inhibitor (TNFi). Dispensing channels included retail, specialty, mail order, long-term care, and other. We included patients continuously enrolled in Medicare Part $D$ who had $\geq 1$ prescription for a specialty medication before the end of June 2010. These patients were followed until the end of 2010. Patients with proportion of days covered $(P D C) \geq 0.8$ were considered adherent. Adherence rates were calculated by weighting for therapeutic class after weighting for drug mix. Multivariable logistic regression analysis examined the association between dispensing channel and adherence.

RESULTS: Of 5,430 patients, 1,248 were dispensed anticancer medications, 1,723 were dispensed DMTs, and 2,459 were dispensed TNFi drugs. About $16 \%$ used specialty, $74 \%$ used retail, $4 \%$ used mail order, $4 \%$ used longterm care, and $3 \%$ used other channels. The distribution pattern was similar when stratified by therapeutic class. In the descriptive analysis, patients using the specialty channel for the anticancer and TNFi classes had $7 \%$ and $10 \%$ higher adherence rates, respectively, compared with retail. For the DMT class, the adherence rate was higher for mail order but similar for retail and specialty channels. Adjusted analysis found that overall, specialty users had $23 \%$ higher odds for being adherent compared with retail users $(P=0.0104)$. For the anticancer and TNFi classes, specialty users had $39 \%(P=0.0311)$ and $55 \%(P=0.0005)$ higher odds, respectively, for being adherent than retail users. For the DMT class, no significant association was observed between dispensing channel and adherence $(P=0.9691)$.

CONCLUSIONS: Nearly three quarters of Medicare patients on specialty therapies included in this study used the retail channel compared with one sixth who used the specialty channel. Overall, specialty channel use was associated with higher adherence compared with retail channel use. However, this relationship varied by therapeutic class. The specialty channel was associated with higher adherence among patients from the anticancer and TNFi classes but not among the DMT class.

J Manag Care Spec Pharm. 2018;24(4):317-26

Copyright $\odot 2018$, Academy of Managed Care Pharmacy. All rights reserved.

\section{What is already known about this subject}

Specialty pharmacies are uniquely positioned to provide patient management, which may improve medication adherence.

Evidence exists that patients from commercial health plans who use specialty pharmacy have higher adherence rates than patients using retail pharmacy.

\section{What this study adds}

Among specialty therapy users from Medicare Part D, 16\% used specialty pharmacy, and $74 \%$ used retail pharmacy to fill their prescriptions

Use of the specialty channel compared with the retail channel was associated with higher adherence to specialty therapies.

For the anticancer and tumor necrosis factor inhibitor classes, specialty pharmacy users had 39\% and 55\% higher odds, respectively, for being adherent than retail pharmacy users.

$\square$ pecialty drugs are medications used to treat chronic, complex conditions. They may cost from $\$ 10,000$ to $\$ 100,000$ or more per course of therapy.1,2 Based on site of care and method of administration, specialty drugs are grouped as office-based infusions or oral/self-injectable drugs. In 2014, rheumatoid arthritis (RA), multiple sclerosis (MS), and cancer were the top 3 specialty therapy classes in terms of spending per member per year. ${ }^{2}$

Medication adherence is defined as "the extent to which a patient acts in accordance with the prescribed interval and dose of a dosing regimen." "Previous research has found that optimal adherence is necessary to achieve adequate tumor response and improve survival among cancer patients, ${ }^{4,5}$ reduce relapses and disability symptoms among MS patients, ${ }^{6,7}$ and achieve better outcomes among patients with RA and Crohn's disease. ${ }^{8,9}$ Nonadherence to specialty drugs has also been associated with higher health care resource utilization and costs to payers. ${ }^{6-11}$

Medication adherence depends on several socioeconomic, access to care, clinical, and health system factors. ${ }^{12,13}$ One of the health system factors may be the type of pharmacy used by patients to refill their prescriptions. In the United States, retail, specialty, and mail order are the most common types of pharmacies used to dispense prescription medications. The type of dispensing channel may influence a patient's drug use by providing routine patient counseling or specialized medication 
management services, or by delivering medications directly to the patient's home or doctor's office.

Treatment with specialty drugs often requires a higher degree of patient education and management than traditional drugs to ensure the accurate and recommended use of medications. Although retail pharmacy can provide services such as patient counseling, the busy retail environment may not allow pharmacists to provide the level of services needed for patients on specialty drugs.

In contrast, specialty pharmacies are better equipped to store and dispense specialty drugs and are focused on providing clinical support services and longitudinal patient management. This support may include patient outreach, monitoring of refill intake, and patient care services..$^{14}$ On the other hand, many specialty pharmacies distribute their products by mail and therefore cannot provide patients with the face-to-face counseling that retail pharmacists could provide. Similar to the specialty channel, mail order also delivers products to patients' homes; however, a majority of products dispensed by mail order are nonspecialty products.

A number of studies have examined the relationship between pharmacy dispensing channel and medication adherence. The majority included patients on traditional drug therapies for diabetes, hypertension, and hypercholesterolemia, ${ }^{15-17}$ and these studies found that patients using the mail order channel had significantly higher adherence rates than patients using the retail channel. ${ }^{15-18}$

A few recent studies have examined this relationship among patients on specialty medications. ${ }^{19-25}$ Barlow et al. (2012) found that patients prescribed etanercept and adalimumab who used the specialty channel had significantly higher adherence rates than patients using the retail channel. ${ }^{19}$ Similar results were found in a study examining adherence to adalimumab. ${ }^{24}$ Tschida et al. (2012) compared adherence rates for oral anticancer drugs and found that adherence was significantly higher among patients who used the specialty channel compared with retail. ${ }^{25}$ A similar conclusion was drawn by Henderson et al. (2014), who examined persistence to a telaprevir-containing hepatitis $C$ regimen. ${ }^{20}$

All the studies that examined the association between dispensing channel and adherence to specialty drugs were conducted among patients enrolled in commercial health plans. Little is known regarding the association between dispensing channel use and adherence to specialty drugs among Medicare Part D patients. Further, the distribution of specialty drugs by dispensing channels among Medicare Part D patients is not well understood.

The objectives of this study were to (a) describe the distribution of specialty drug dispensing across channels among Medicare Part D patients and (b) examine the association between dispensing channel use and adherence to specialty drugs in this population. We hypothesized that patients using the specialty channel would have higher rates of adherence compared with other dispensing channels for the therapeutic classes included in this study.

\section{Methods}

\section{Data Source}

This was a cross-sectional study that used 2010 Medicare Part D data from a 5\% random sample of Medicare beneficiaries. We used data from Prescription Drug Event (PDE), Pharmacy Characteristics, Plan Characteristics, and Master Summary files. The PDE file provided details regarding generic drug name, date of dispensing, days supply, drug cost reimbursed by Medicare, and out-of-pocket (OOP) costs. The Pharmacy Characteristics file provided data on the pharmacy dispensing channel. ${ }^{26}$

\section{Sample Selection}

We defined specialty drugs using the definition from the Centers for Medicare \& Medicaid Services as any oral or selfinjectable drug with mean costs $\geq \$ 600$ per month. ${ }^{27}$ The top 300 products were identified based on gross drug cost, which is the amount reimbursed by Medicare. From these, we identified 13 specialty drugs. These products were further classified into 3 therapeutic classes-(a) anticancer, (b) disease-modifying therapy (DMT) for MS, and (c) tumor necrosis factor inhibitor (TNFi), commonly used for conditions such as RA. The following drugs were identified using generic drug names:

- Anticancer: lenalidomide, imatinib mesylate, erlotinib hydrochloride, thalidomide, sorafenib tosylate, sunitinib malate, and dasatinib

- DMTs:glatirameracetate, interferonbeta-la, interferonbeta-1b, and interferon beta-la/albumin

- TNFi: etanercept and adalimumab

We included patients who had at least 1 claim for 1 of the above therapies in 2010. In order to measure adherence for at least 6 months, we limited our sample to patients who had a prescription dispensed before the end of June 2010. These patients were followed until the end of December 2010. We excluded patients who died or were not continuously enrolled in Medicare Part D for 2010 and those who filled prescriptions from more than 1 type of pharmacy $(n=641)$. The sample selection process is shown in Appendix A (available in online article).

\section{Study Measures}

Dispensing Channel. Type of pharmacy dispensing channel was the main independent variable. Definitions from Medicare were used to categorize patients into retail, mail order, specialty, long-term care, and other channels. ${ }^{26}$ The specialty channel was defined as "a pharmacy that dispenses generally low volume and high-cost medications to patients that have generally chronic, complex and potentially life-threatening conditions." Often these therapies require specialized delivery and administration. The retail channel was defined as "a 


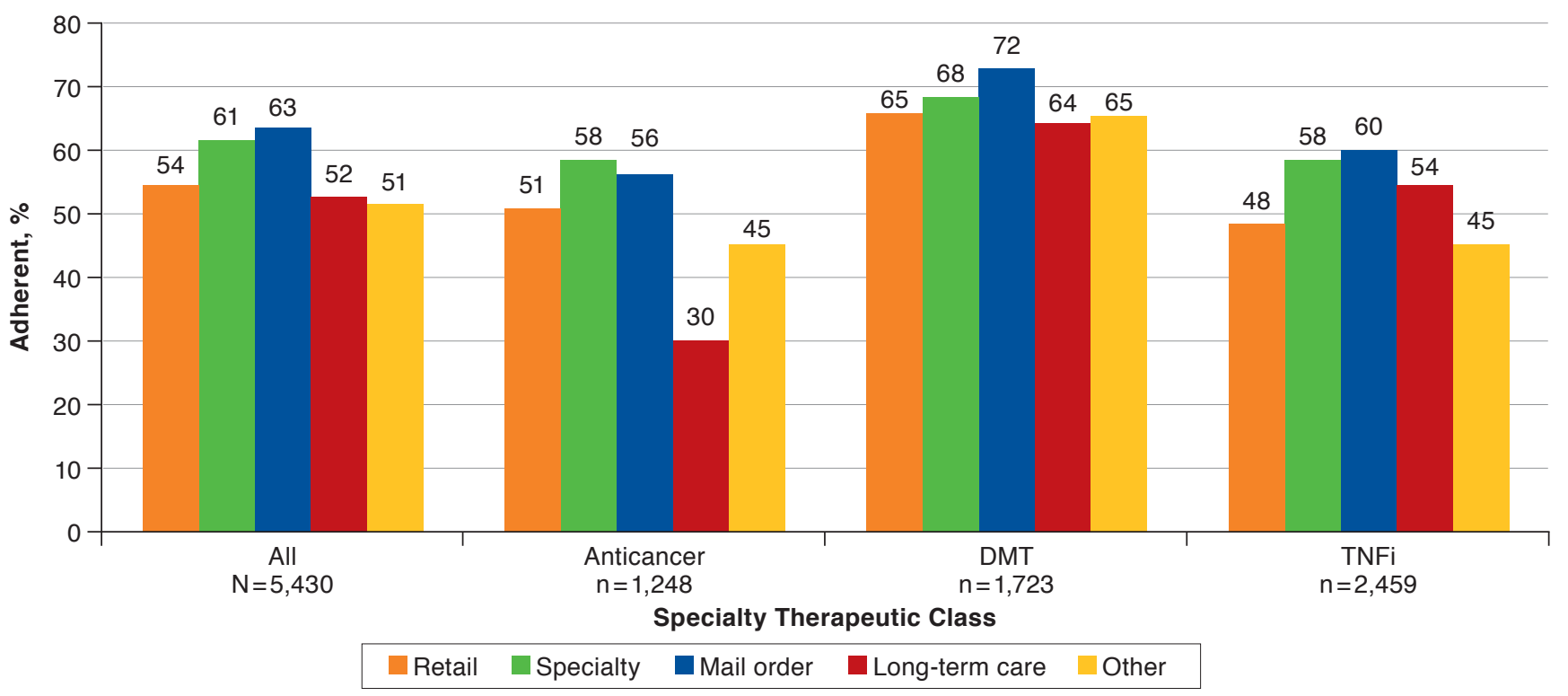

DMT = disease-modifying therapy; TNFi=tumor necrosis factor inhibitor.

community/retail pharmacy where pharmacists dispense medications for a local patient population, counsel patients and caregivers, administer vaccinations, and provide other professional services." The mail order channel was defined as "a pharmacy where pharmacists dispense prescriptions, in accordance with federal and state law, using common carriers to deliver the medications to patients or their caregivers." The long-term care channel was defined as "a pharmacy that dispenses medications delivered to patients residing within an intermediate or skilled nursing facility, including intermediate care facilities." We combined home infusion therapy, institutional, clinic, managed care organization, compounding pharmacy, or others into other type due to low frequencies of patients using these channels.

Medication Adherence. Adherence was measured in proportion of days covered (PDC) for a specific specialty drug, calculated using the the following formula: $\mathrm{PDC}=$ sum of days supply/number of days from the first prescription in 2010 until the end of the study period.

Patients with PDC values $\geq 0.8$ were considered to be adherent to specialty drug therapy. Since each dispensing channel dispensed a different proportion of TNFi and anticancer drugs and DMTs, and because adherence rates for the 3 therapeutic classes would depend on adherence to individual drugs from those classes, we calculated weighted adherence rates by assigning the average drug distribution to each therapeutic class and average therapeutic class distribution to each dispensing channel. For example, to calculate adherence to the TNFi class for the specialty channel, we first calculated the proportion of patients adherent to adalimumab only (58.1\%), etanercept only (57.1\%), or adalimumab/etanercept ( $>1$ therapy) for the specialty channel (77.8\%). These figures were then multiplied by the proportion of patients from the TNFi class on each of these medications (adalimumab only [41.8\%], etanercept only [54.6\%], or adalimumab/eanercept [3.6\%]). Weighted adherence rate for the TNFi class was calculated as ([58.1\% $\times$ $41.8 \%]+[57.1 \% \times 54.6 \%]+[77.8 \% \times 3.6 \%])=58.3 \%$ (see Figure 1, adherence rate of TNFi for the specialty channel). To calculate the weighted adherence rate for a specific channel, class-level adherence rates for that channel were multiplied by the proportion of patients from each therapeutic class.

Other Variables. These variables included patients' age, sex, race, low-income subsidy (LIS) status, type of plan (prescription drug plan/health maintenance organization plan), OOP cost per 30 days supply, days supply per prescription, and drug burden. Some anticancer drugs such as sunitinib have recommended time off from the therapy before the next refill. We corrected days supply for such drugs to accurately reflect their therapeutic regimen. Since we did not have data on inpatient and outpatient claims needed to measure comorbidity burden, we used drug burden as a proxy. Drug burden was measured as the total number of unique prescription drugs taken by patients in 2010. 


\section{FIGURE 2 Dispensing Channel Use by Therapeutic Class}

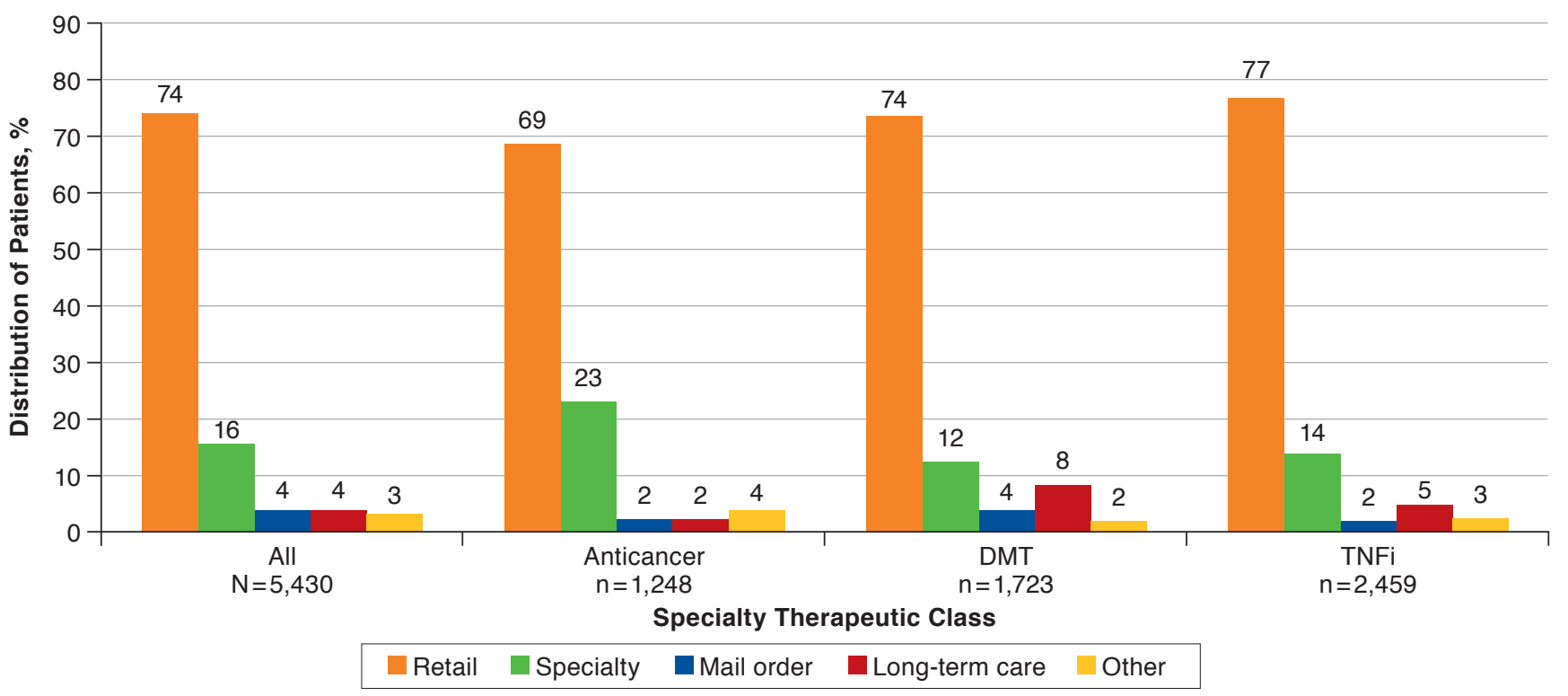

$D M T=$ disease- modifying therapy; $T N F i=$ tumor necrosis factor inhibitor

\section{Statistical Analysis}

Patient characteristics were compared across dispensing channels for all 3 therapeutic classes using chi-square tests for categorical variables and analysis of variance for continuous variables. We also described the proportion of patients on specialty drugs by therapeutic class and type of dispensing channel (see Figure 2). In the unadjusted analyses, multiple comparison tests were used to compare weighted adherence rates across channels for all patients and by therapeutic class. Multivariable (binary) logistic regression was used to assess the association between dispensing channel and adherence to specialty drugs after controlling for other covariates. The OOP cost and LIS status were highly correlated, so only the OOP cost was included in the multivariable analyses. All analyses were conducted at an a level of 0.05 using SAS software package 9.4 (SAS Institute, Cary, NC) and Microsoft Excel 2016 (Redmond, WA).

\section{Sensitivity Analysis}

For the sensitivity analysis, we first included patients who used more than 1 type of pharmacy but used a specific channel to refill $75 \%$ of their prescriptions. We assigned the most frequently used channel among these patients as their primary dispensing channel and re-examined the relationship between type of dispensing channel and adherence. Second, we varied the definition of adherence from $P D C \geq 0.8$ to $P D C \geq 0.7$ and $P D C \geq 0.9$. Third, we assessed the effect of dispensing channel on adherence by using PDC as a continuous variable. Fourth, we analyzed only patients aged $\geq 65$ years, and fifth, we controlled for Medicare Part D benefit phase design (time spent in the coverage gap and catastrophic coverage phases), as Medicare patients are often exposed to the coverage gap and must pay significant OOP costs.

\section{Results}

\section{Sample Characteristics}

Of 5,430 patients who met the inclusion/exclusion criteria, 1,248 were dispensed anticancer therapies, 1,723 were dispensed DMTs, and 2,459 were dispensed TNFi drugs. Characteristics of patients included in this study can be found in Table 1. For the anticancer class, patients were similar for demographic characteristics and drug burden across dispensing channels. However, the proportion of patients with LIS was significantly higher (59\%) among the long-term care channel compared with retail, mail order, specialty, and other channels (18\%-40\%). In addition, mean days supply per prescription for mail order was significantly higher (44.2 days) compared with other channels (about 30 days).

For the DMT class, average age and drug burden were significantly higher among patients using long-term care compared with other channels. In addition, the mail order channel had significantly higher days supply per prescription (72.8 days) compared with other channels. For the TNFi class, the average age for patients from the mail order and long-term care channels was higher (67-68 years) than the retail and specialty 


\section{TABLE 1 Patient Characteristics Across Dispensing Channels by Therapeutic Class ( $N=5,430$ )}

\begin{tabular}{|c|c|c|c|c|c|c|}
\hline Variables & $\begin{array}{c}\text { Retail } \\
(n=4,023)\end{array}$ & $\begin{array}{l}\text { Specialty } \\
(\mathrm{n}=842)\end{array}$ & $\begin{array}{c}\text { Long-term Care } \\
(\mathbf{n}=204)\end{array}$ & $\begin{array}{l}\text { Mail Order } \\
(\mathrm{n}=213)\end{array}$ & \multicolumn{2}{|c|}{$\begin{array}{c}\text { Other } \\
(n=148)\end{array}$} \\
\hline Anticancer class $(n=1,248)$ & $n=863$ & $\mathrm{n}=286$ & $\mathrm{n}=22$ & $\mathrm{n}=28$ & \multicolumn{2}{|c|}{$\mathrm{n}=49$} \\
\hline Age, years (mean, SD) & $72.2 \quad(11.3)$ & $72.0 \quad(8.9)$ & $69.7(14.1)$ & $70.9 \quad(10.1)$ & 73.2 & $(7.9)$ \\
\hline Sex, \% female & 60.1 & 53.5 & 54.6 & 57.1 & & 51.0 \\
\hline Race, \% Caucasian & 73.4 & 74.8 & 77.3 & 92.9 & & 79.6 \\
\hline LIS, \% ${ }^{\mathrm{a}}$ & 38.2 & 23.4 & 59.1 & 17.9 & & 39.8 \\
\hline PDP vs. HMO plan enrollee, $\%^{a}$ & 68.3 & 61.9 & 59.1 & 67.9 & & 51.0 \\
\hline OOP cost per 30 days supply, \$ (median, IQR) & $438 \quad(766)$ & $(807)$ & $(598)$ & $543(1,144)$ & 73 & $(695)$ \\
\hline OOP cost per 30 days supply non-LIS only, \$ (median, IQR) & $682 \quad(444)$ & $(452)$ & $(462)$ & $596(1,047)$ & 644 & $(582)$ \\
\hline Days supply per claim (mean, SD)a & $30.4 \quad(7.6)$ & $(11.9)$ & $(6.5)$ & $44.2(26.2)$ & 31.9 & $(9.8)$ \\
\hline Drug burden, \# (mean, SD) & $12.4 \quad(7.0)$ & $12.9 \quad(7.6)$ & $13.1 \quad(5.9)$ & $10.5 \quad(4.8)$ & 13.6 & $(9.6)$ \\
\hline DMT class $(n=1,723)$ & $\mathrm{n}=1,267$ & $\mathrm{n}=212$ & $\mathrm{n}=138$ & $\mathrm{n}=70$ & \multicolumn{2}{|c|}{$\mathrm{n}=36$} \\
\hline Age, years (mean, SD)a & $52.9 \quad(11.0)$ & $53.6(10.8)$ & $58.6 \quad(11.2)$ & $53.0(12.5)$ & 54.8 & $(11.6)$ \\
\hline Sex, \% female & 79.3 & 77.4 & 72.5 & 78.6 & & 91.7 \\
\hline Race, \% Caucasian & 80.6 & 78.8 & 72.5 & 74.3 & & 77.8 \\
\hline LIS, \% & 66.9 & 74.1 & 97.8 & 71.4 & & 58.3 \\
\hline PDP vs. HMO plan enrollee, $\%$ a & 69.6 & 70.8 & 84.8 & 78.6 & & 38.9 \\
\hline OOP cost per 30 days supply, \$ (median, IQR) & $2(447)$ & $(65)$ & $(0)$ & $(26)$ & 2 & $(39)$ \\
\hline OOP cost per 30 days supply non-LIS only, \$ (median, IQR)a & $497 \quad(109)$ & $(187)$ & $(640)$ & $(468)$ & 339 & $(532)$ \\
\hline Days supply per claim (mean, SD)a & $(6.8)$ & $33.0(14.0)$ & $(6.4)$ & $72.8(22.2)$ & 33.9 & $(14.4)$ \\
\hline Drug burden, \# (mean, SD) ${ }^{\mathrm{a}}$ & $11.4 \quad(7.4)$ & $10.1 \quad(6.7)$ & $(8.2)$ & $11.2 \quad(8.0)$ & 9.7 & $(6.5)$ \\
\hline TNFi class $(n=2,459)$ & $\mathrm{n}=1,893$ & $\mathrm{n}=344$ & $n=44$ & $\mathrm{n}=115$ & \multicolumn{2}{|c|}{$n=63$} \\
\hline Age, years $($ mean, SD)a & $63.4(13.3)$ & $64.9(12.3)$ & $67.0(16.5)$ & $68.1(11.2)$ & 64.0 & $(12.9)$ \\
\hline Sex, \% female & 74.9 & 70.9 & 81.8 & 67.0 & & 81.0 \\
\hline Race, \% Caucasian ${ }^{a}$ & 78.3 & 79.1 & 79.6 & 87.8 & & 63.5 \\
\hline LIS, $\%^{\mathrm{a}}$ & 63.4 & 45.2 & 91.9 & 33.0 & & 57.1 \\
\hline PDP vs. HMO plan enrollee, $\%^{a}$ & 69.5 & 58.1 & 93.2 & 62.6 & & 34.9 \\
\hline OOP cost per 30 days supply, $\$$ (median, IQR) & $3(319)$ & $(438)$ & $(2)$ & $(378)$ & 3 & $(159)$ \\
\hline OOP cost per 30 days supply non-LIS only, \$ (median, IQR)a & $430 \quad(506)$ & $417 \quad(536)$ & (99) & $54 \quad(385)$ & 359 & $(436)$ \\
\hline Days supply per claim (mean, SD)a & $30.2(10.2)$ & $35.3(18.3)$ & $(5.8)$ & $69.2(23.3)$ & 31.7 & $(13.2)$ \\
\hline Drug burden, \# (mean, SD)a & $13.6 \quad(7.5)$ & $12.8 \quad(6.7)$ & $(7.8)$ & $12.5 \quad(6.7)$ & 12.6 & $(6.0)$ \\
\hline
\end{tabular}

astatistically significant, $P<0.05$.

$D M T=$ disease-modifying therapy; $H M O=$ health maintenance organization; $I Q R=$ interquartile range; $L I S=$ low-income subsidy; $O O P=$ out-of-pocket; $P D P=$ prescription drug plan; $S D=$ standard deviation; TNFi= tumor necrosis factor inhibitor

channels (about 64 years). The mail order channel had a higher proportion of Caucasians, lower OOP cost, and higher days supply per prescription compared with other channels.

\section{Distribution of Specialty Therapies Across Dispensing Channels}

Of 5,430 patients on specialty therapies, 4,023 (74.1\%) used retail, 842 (15.5\%) used specialty, 213 (3.9\%) used mail order, 204 (3.8\%) used long-term care, and 148 (2.7\%) used other channels. A similar distribution pattern was observed when the analysis was stratified by therapeutic class (Figure 2). Retail was the most commonly used channel among patients from the anticancer, DMT, and TNFi classes $(69 \%, 74 \%$, and $77 \%$, respectively), followed by the specialty channel (23\%, $12 \%, 14 \%$, respectively). The proportion of mail order users was slightly higher for the DMT class (8\%) compared with the anticancer (2\%) and TNFi classes (5\%). The distribution of each specialty drug by dispensing channels can be found in Appendix B (available in online article).

Each dispensing channel differed in the distribution of prescriptions across therapeutic classes. The most common therapeutic class dispensed through specialty channels was TNFi (41\%), followed by anticancer (34\%) and DMT (25\%). For retail channels, it was TNFi (47\%), followed by DMT (32\%) and anticancer (21\%). A similar pattern was observed for mail order channels. In contrast, the most common class dispensed by long-term care channels was DMT (68\%), followed by TNFi (22\%) and anticancer (11\%).

\section{Unadjusted Adherence Rates Across Dispensing Channels Overall and by Therapeutic Class}

When all therapeutic classes were combined, adherence rates were $63 \%$ for mail order, $61 \%$ for specialty, $54 \%$ for retail, $52 \%$ for long-term care, and 51\% for other channels. Multiple 


\begin{tabular}{|c|c|c|c|c|}
\hline$A L$ & $\begin{array}{l}\text { Asso } \\
\text { Disp } \\
\text { Ther }\end{array}$ & $\begin{array}{l}\text { ition Bet } \\
\text { sing Cha } \\
\text { eutic Cla }\end{array}$ & $\begin{array}{l}\text { en Phal } \\
\text { el and }\end{array}$ & $\begin{array}{l}\text { ey } \\
\text { erence by }\end{array}$ \\
\hline $\begin{array}{l}\text { Pharmacy } \\
\text { Dispensing } \\
\text { Channel }\end{array}$ & $\begin{array}{c}\text { Alla } \\
(\mathrm{N}=5,430) \\
\text { OR }(95 \% \mathrm{CI})\end{array}$ & $\begin{array}{c}\text { Anticancerb } \\
(\mathrm{n}=1,248) \\
\text { OR }(95 \% \mathrm{CI})\end{array}$ & $\begin{array}{c}\text { DMTb }^{\mathrm{b}} \\
(\mathrm{n}=1,723) \\
\text { OR }(95 \% \mathrm{CI})\end{array}$ & $\begin{array}{c}\text { TNFi }^{\mathrm{b}} \\
(\mathrm{n}=2,459) \\
\text { OR }(95 \% \mathrm{CI})\end{array}$ \\
\hline Retail & Reference & Reference & Reference & Reference \\
\hline Specialty & $\begin{array}{c}1.23^{c} \\
(1.05-1.44)\end{array}$ & $\begin{array}{c}1.39 c \\
(1.03-1.86)\end{array}$ & $\begin{array}{c}1.01 \\
(0.73-1.39)\end{array}$ & $\begin{array}{c}1.55^{\mathrm{c}} \\
(1.21-1.98)\end{array}$ \\
\hline Mail order & $\begin{array}{c}0.75 \\
(0.52-1.07)\end{array}$ & $\begin{array}{c}0.70 \\
(0.31-1.61)\end{array}$ & $\begin{array}{c}0.87 \\
(0.41-1.85)\end{array}$ & $\begin{array}{c}0.79 \\
(0.48-1.28)\end{array}$ \\
\hline $\begin{array}{l}\text { Long-term } \\
\text { care }\end{array}$ & $\begin{array}{c}0.87 \\
(0.64-1.19)\end{array}$ & $\begin{array}{c}0.56 \\
(0.23-1.40)\end{array}$ & $\begin{array}{c}0.87 \\
(0.58-1.31)\end{array}$ & $\begin{array}{c}1.05 \\
(0.56-1.96)\end{array}$ \\
\hline Other & $\begin{array}{c}0.80 \\
(0.57-1.13)\end{array}$ & $\begin{array}{c}0.73 \\
(0.39-1.36)\end{array}$ & $\begin{array}{c}0.94 \\
(0.46-1.93)\end{array}$ & $\begin{array}{c}0.86 \\
(0.51-1.45)\end{array}$ \\
\hline
\end{tabular}

aModel adjusted for age, sex, race, drug burden, days supply per claim, plan type, $O O P$ cost, and therapeutic class.

${ }^{b}$ Model adjusted for age, sex, race, drug burden, days supply per claim, plan type, OOP cost, and drug mix.

cStatistically significant, $P<0.05$

$C I=$ confidence interval; $D M T=$ disease - modifying therapy; $O O P=$ out-of-pocket; $\mathrm{OR}=$ odds ratio; $\mathrm{TNFi}=$ tumor necrosis factor inhibitor

comparison tests indicated that adherence rates for mail order were significantly different $(P=0.046)$ from other channels. No other comparisons were statistically significant.

For the anticancer class, adherence rates were highest for the specialty channel followed by the mail order, retail, other, and long-term care channels. Patients from the specialty channel had a significantly higher $(P=0.043)$ adherence rate compared with patients from the long-term care channel. For the DMT class, patients from the mail order channel had higher adherence rates compared with other channels; however, differences were not statistically significant. For the TNFi class, adherence rates were highest for mail order (60\%), followed by specialty (58\%), long-term care (54\%), retail (48\%), and other (45\%) channels. Comparisons between specialty and other, and mail order and other were statistically significant (Figure 1).

\section{Association Between Dispensing Channel and Medication Adherence Overall}

Multivariable logistic regression analysis indicated that when all the therapeutic classes are combined, patients from the specialty channel had 1.23 times higher odds for being adherent compared with patients from retail $(P=0.0104)$ after controlling for therapeutic class and other covariates in the model. Comparisons between retail and long-term care and other channels were not statistically significant (Table 2).

\section{Association Between Dispensing Channel and Medication Adherence by Therapeutic Class}

Multivariable logistic regression analysis found that for the anticancer class, patients using the specialty channel had 1.39 times higher odds for being adherent compared with retail $(P=0.0311)$ No other comparisons between dispensing channels were statistically significant. For the TNFi class, patients from the specialty channel had 1.55 times higher odds for being adherent than retail $(P=0.0005)$. For the DMT class, patients from the specialty channel had 1.01 times higher odds for being adherent compared with patients from retail. However, this relationship was not statistically significant $(P=0.9691)$. Comparisons between retail and long-term care, mail order, and other channels were not statistically significant for any of the 3 therapeutic classes (Table 2).

We ran additional statistical models to compare the specialty channel to the mail order and other channels. For the TNFi class, we found that patients from the specialty channel had 1.97 times $(P=0.0096)$ and 1.81 times $(P=0.0388)$ higher odds for being adherent, respectively. No difference in adherence risk was found for specialty versus mail order and other comparisons for the anticancer and DMT classes (results not shown).

\section{Sensitivity Analyses}

Our main findings were consistent with results obtained after including patients who used multiple channels but used a specific channel for $\geq 75 \%$ of their specialty prescriptions (Table 3 ). They were also consistent when we defined adherence as $P D C \geq 0.7$ and when PDC was measured as a continuous outcome. When PDC was defined as $\mathrm{PDC} \geq 0.9$, findings for the DMT and TNFi classes were similar to our main findings. However, no significant association was observed between adherence and dispensing channel for the anticancer class (Table 3). The analysis including only older patients indicated findings similar to the main results. However, when all classes were combined, the odds ratio (OR) for adherence for specialty was no longer statistically significant. The ORs for the TNFi and anticancer classes remained statistically significant.

Controlling for Part D benefit design did not alter the relationship observed in our main analysis between dispensing channel and adherence for either of the therapeutic classes. However, when all classes were combined, the OR for the specialty channel was no longer statistically significant compared with retail (Table 3). In terms of an independent effect of benefit phase design, the odds of being adherent decreased significantly with an increase in time spent in the coverage gap. The odds of being adherent increased significantly as patients spent more time in catastrophic coverage (results not shown).

\section{Discussion}

This study examined the dispensing channel used by Medicare patients for self-administered specialty drugs and the association between dispensing channel use and medication adherence. In the Medicare Part D population, retail was the most commonly used channel. Only $16 \%$ of patients on specialty therapies used the specialty channel. This proportion was higher 


\section{TABLE 3 Results of Sensitivity Analyses for Association of Dispensing Channel and Adherence} by Therapeutic Class

\begin{tabular}{|c|c|c|c|c|c|c|c|}
\hline Dispensing Channel & \multicolumn{2}{|c|}{$\begin{array}{c}\text { Alla } \\
\text { OR }(95 \% \text { CI })\end{array}$} & \multicolumn{2}{|c|}{$\begin{array}{l}\text { Anticancer } \\
\text { OR }(95 \% \mathrm{CI})\end{array}$} & $\begin{array}{c}\text { DMT }^{\mathrm{b}} \\
\text { OR }(95 \% \mathrm{CI})\end{array}$ & \multicolumn{2}{|c|}{$\begin{array}{c}\text { TNFi }^{\mathrm{b}} \\
\text { OR }(95 \% \mathrm{CI})\end{array}$} \\
\hline $\begin{array}{l}\text { Patients using a specific channel } \\
\text { for } \geq 75 \% \text { of prescriptions }\end{array}$ & \multicolumn{2}{|c|}{$(\mathrm{N}=5,753)$} & \multicolumn{2}{|c|}{$(n=1,315)$} & $(\mathrm{n}=1,835)$ & \multicolumn{2}{|c|}{$(\mathrm{n}=2,603)$} \\
\hline Retail & \multicolumn{2}{|c|}{ Reference } & \multicolumn{2}{|c|}{ Reference } & Reference & \multicolumn{2}{|c|}{ Reference } \\
\hline Specialty & $1.28^{\mathrm{c}}$ & $(1.10-1.49)$ & $1.40^{\mathrm{c}}$ & $(1.05-1.85)$ & $1.07 \quad(0.79-1.45)$ & $1.58^{\mathrm{c}}$ & $(1.26-1.99)$ \\
\hline Mail order & 0.86 & $(0.63-1.19)$ & 0.73 & $(0.33-1.62)$ & $(0.48-1.78)$ & 0.96 & $(0.48-1.28)$ \\
\hline Long-term care & 0.87 & $(0.65-1.17)$ & 0.48 & $(0.20-1.16)$ & $(0.58-1.26)$ & 1.23 & $(0.68-2.24)$ \\
\hline Other & 0.82 & $(0.59-1.14)$ & 0.70 & $(0.38-1.30)$ & $1.09 \quad(0.54-2.20)$ & 0.83 & $(0.49-1.38)$ \\
\hline Patients aged $\geq 65$ years & \multicolumn{2}{|c|}{$(\mathrm{N}=2,772)$} & \multicolumn{2}{|c|}{$(\mathrm{n}=1,064)$} & $(\mathrm{n}=289)$ & \multicolumn{2}{|c|}{$(\mathrm{n}=1,397)$} \\
\hline Retail & \multicolumn{2}{|c|}{ Reference } & \multicolumn{2}{|c|}{ Reference } & Reference & \multicolumn{2}{|c|}{ Reference } \\
\hline Specialty & 1.22 & $(0.99-1.50)$ & $1.41^{\mathrm{c}}$ & $(1.03-1.94)$ & $0.53 \quad(0.24-1.18)$ & $1.41^{\mathrm{c}}$ & $(1.02-1.93)$ \\
\hline Mail order & 0.91 & $(0.57-1.45)$ & 0.73 & $(0.29-1.87)$ & NA & 0.92 & $(0.52-1.63)$ \\
\hline Long-term care & 0.63 & $(0.39-1.01)$ & 0.44 & $(0.14-1.35)$ & $(0.28-1.81)$ & 0.85 & $(0.39-1.88)$ \\
\hline Other & 0.69 & $(0.43-1.09)$ & 0.55 & $(0.28-1.08)$ & NA & 0.82 & $(0.41-1.63)$ \\
\hline $\begin{array}{l}\text { Inclusion of Part D benefit phase } \\
\text { covariates }^{\mathrm{d}}\end{array}$ & \multicolumn{2}{|c|}{$(\mathrm{N}=4,891)$} & \multicolumn{2}{|c|}{$(n=1,108)$} & $(n=1,623)$ & \multicolumn{2}{|c|}{$(\mathrm{n}=2,159)$} \\
\hline Retail & \multicolumn{2}{|c|}{ Reference } & & erence & Reference & & erence \\
\hline Specialty & 1.15 & $(0.96-1.38)$ & $1.40^{\mathrm{c}}$ & $(1.02-1.93)$ & $0.91 \quad(0.63-1.32)$ & $1.48^{\mathrm{c}}$ & $(1.09-2.00)$ \\
\hline Mail order & 0.51 & $(0.32-0.81)$ & 0.44 & $(0.17-1.16)$ & $(0.20-1.31)$ & 0.59 & $(0.30-1.17)$ \\
\hline Long-term care & 0.75 & $(0.54-1.06)$ & 0.47 & $(0.18-1.24)$ & $(0.42-1.05)$ & 0.80 & $(0.39-1.61)$ \\
\hline Other & 0.75 & $(0.50-1.14)$ & 0.63 & $(0.32-1.24)$ & $0.71 \quad(0.30-1.69)$ & 0.96 & $(0.49-1.87)$ \\
\hline Adherence definitions & & $5,430)$ & & $1,248)$ & $(n=1,723)$ & & $2,459)$ \\
\hline $\mathrm{PDC} \geq 0.7$ & & & & & & & \\
\hline Retail & & erence & & erence & Reference & & erence \\
\hline Specialty & $1.23^{\mathrm{c}}$ & $(1.04-1.45)$ & $1.55^{\mathrm{c}}$ & $(1.14-2.12)$ & $0.98 \quad(0.69-1.39)$ & $1.50^{c}$ & $(1.15-1.94)$ \\
\hline Mail order & 0.66 & $(0.45-0.98)$ & 0.59 & $(0.25-1.39)$ & $(0.24-1.28)$ & 0.80 & $(0.47-1.36)$ \\
\hline Long-term care & 0.88 & $(0.63-1.21)$ & 0.59 & $(0.23-1.47)$ & $(0.62-1.51)$ & 0.83 & $(0.44-1.57)$ \\
\hline Other & 0.69 & $(0.49-0.98)$ & 0.69 & $(0.37-1.29)$ & $(0.40-1.94)$ & 0.69 & $(0.41-1.17)$ \\
\hline$P D C \geq 0.9$ & & & & & & & \\
\hline Retail & & erence & & erence & Reference & & erence \\
\hline Specialty & 1.12 & $(0.95-1.30)$ & 1.26 & $(0.93-1.71)$ & $0.91 \quad(0.67-1.22)$ & $1.51^{\mathrm{c}}$ & $(1.18-1.94)$ \\
\hline Mail order & 0.76 & $(0.54-1.08)$ & 0.89 & $(0.40-2.05)$ & $(0.44-1.72)$ & 0.81 & $(0.50-1.32)$ \\
\hline Long-term care & 0.71 & $(0.53-0.97)$ & 0.60 & $(0.23-1.55)$ & $(0.47-1.01)$ & 0.76 & $(0.39-1.48)$ \\
\hline Other & 0.86 & $(0.60-1.21)$ & 0.79 & $(0.41-1.51)$ & $(0.29-1.16)$ & 1.26 & $(0.74-2.16)$ \\
\hline PDC as continuous variable & & & & & & & \\
\hline & & $5 \% \mathrm{CI})$ & & $5 \% \mathrm{CI})$ & $\beta(95 \% \mathrm{CI})$ & & $5 \% \mathrm{CI})$ \\
\hline Retail & & erence & & erence & Reference & & erence \\
\hline Specialty & $0.023 \mathrm{c}$ & $.003-0.043)$ & 0.054 & $0.015-0.093)$ & $0.005(-0.031-0.042)$ & $0.047 \mathrm{c}$ & $0.016-0.079)$ \\
\hline Mail order & -0.039 & $.083-0.005)$ & -0.036 & $0.142-0.071)$ & $-0.053(-0.134-0.028)$ & -0.006 & $0.066-0.054)$ \\
\hline Long-term care & -0.029 & $0.068-0.010)$ & -0.038 & $0.156-0.079)$ & $-0.011 \quad(-0.058-0.036)$ & -0.070 & $0.149-0.012)$ \\
\hline Other & -0.042 & $0.087-0.002)$ & -0.040 & $0.112-0.040)$ & $-0.028 \quad(-0.111-0.055)$ & -0.028 & $0.111-0.055)$ \\
\hline 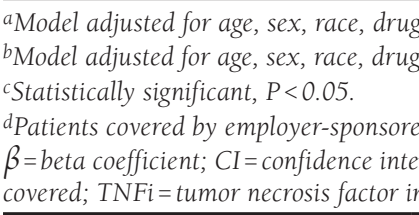 & $\begin{array}{l}\text { urden, da } \\
\text { urden, da } \\
\text { plan and } \\
\text { al; DMT } \\
\text { ibitor. }\end{array}$ & $\begin{array}{l}\text { supply per clai } \\
\text { supply per clail } \\
\text { grams of All-I } \\
\text { sease-modifyin }\end{array}$ & $\begin{array}{l}n \text { type, } \\
n \text { type, } \mathrm{C} \\
\text { Care } \mathrm{x} \\
\text { apy; NA }\end{array}$ & $\begin{array}{l}\text { cost, and ther } \\
\text { cost, and dru\& } \\
\text { excluded. } \\
\text { t applicable; } 0\end{array}$ & ut-of-pocket; OR=odds $r \mathrm{a}$ & $C=p r c$ & on of days \\
\hline
\end{tabular}

among patients from the anticancer class (23\%) compared with the TNFi (14\%) and DMT classes (12\%). Considerably lower proportions of patients on specialty medications filled prescriptions through mail order, long-term care, and other channels for the therapeutic classes included in this study.
To our knowledge, this is the first study to describe the distribution of specialty drug dispensing by pharmacy channel among Medicare Part D patients. The prevalence of specialty channel use among Medicare patients was significantly lower than the prevalence reported by studies using commercial 
health plan databases. ${ }^{19,24}$ In our study, only $14 \%$ of patients from the TNFi class used the specialty channel. In contrast, $70 \%$ patients on TNFi medications from the study by Liu et al. (2010) used the specialty channel. ${ }^{24}$ This could be because private health plans require or encourage patients on specialty therapies to use specialty pharmacy; however, no such requirement exists for Medicare patients.

Descriptive analysis suggested that adherence rates were higher for the specialty channel compared with retail for the anticancer and TNFi classes, but was similar for the DMT class. Results from multivariable analysis suggested that when all classes were combined, patients on the specialty channel were $23 \%$ more likely to be adherent to medications compared with those using retail. The adherence rates of patients from the long-term care channel did not differ from retail. Although long-term care patients receive assistance from staff to take their medications, these patients also have higher comorbidities and complications than patients from retail, which could result in higher physician-recommended medication discontinuation.

For the anticancer and TNFi classes, patients using the specialty channel were more likely to be adherent compared with patients using the retail channel. However, a similar relationship was not observed for the DMT class. In the descriptive analysis, the adherence rate for the DMT class was highest for the mail order channel. Patients using mail order also had higher adherence rates compared with retail for the anticancer and TNFi classes. This could be because mail order pharmacies dispense longer days supply. In this study, the average days supply per claim for mail order was significantly higher than for other channels. After adjusting for days supply and other covariates in the multivariable model, we found that the mail order channel did not have higher adherence rates than the retail channel for any of the therapeutic classes.

Our findings related to the relationship between dispensing channel use and adherence were, for the most part, consistent with findings from studies that included patients enrolled in commercial health plans. ${ }^{19,21,24,25}$ In our study, for the anticancer class, patients using the specialty channel were 39\% more likely to be adherent compared with patients using the retail channel. This was consistent with Tschida et al., who found that cancer patients enrolled in the specialty channel had significantly higher weighted medication possession ratio compared with patients from the retail channel..$^{25}$

In our study, specialty channel users from the TNFi class were 55\% more likely to be adherent than retail users. Liu et al., too, found that patients using the specialty channel had 16\% higher adherence than retail users. ${ }^{24}$ Findings for the DMT class were not consistent with the literature.

In our study, adherence rates to DMTs were similar across all channels. In contrast, previous studies indicated higher adherence rates for the specialty channel compared with the retail channel. ${ }^{22,23}$ One possible reason for this inconsistency could be differences in the number of Medicare versus commercial insurance patients who are prevalent users of DMTs. The age of onset for MS is between 20 and 50 years. ${ }^{28}$ Therefore, MS patients who qualify for Medicare are more likely to be continuing (prevalent) users of DMTs. Prevalent users have more experience with their therapies and therefore may not benefit, or benefit as much, from services provided by specialty pharmacies.

In contrast, patients from commercial health plans are more likely to be in the earlier relapse-remitting stage of MS and be new users of DMTs. These patients are more likely to benefit from services provided by specialty pharmacies. In contrast to MS patients on Medicare, patients on anticancer and TNFi therapies could be more likely to be new users of therapies or be in disease stages where adherence could improve survival or functional outcomes. Such patients are more likely to benefit from the disease management and patient outreach programs offered at specialty pharmacies.

Results from sensitivity analyses suggested that our findings were robust to the definition of adherence. Findings were also consistent after including patients who used 1 channel for at least $75 \%$ of their prescriptions, among a subgroup including only older adults, and when including Part D benefit phases as covariates. Since this study included only patients on specialty medications, almost all the patients (99\%) from each dispensing channel reached the coverage gap within the first 60 days of the new plan year and remained in the coverage gap for approximately 56 days. Therefore, even though benefit phases were independently associated with adherence, this relationship did not vary across dispensing channels.

Our findings provide some evidence that Medicare patients on specialty therapies can benefit more from specialty pharmacy compared with retail. Several studies conducted on commercial health plans databases support this conclusion. However, more research is needed specifically among the Medicare population, because we found that specialty drug distribution in the Medicare population was much different from the distribution observed among patients from commercial health plans.

Our study included the top 13 self-administered specialty therapies by Medicare cost in 2010. Several specialty drugs have been approved since 2010. Future research in this area may include newer specialty drugs approved for MS, hepatitis C, rheumatic diseases, and cancer to replicate our study findings. Future studies may use medical data from Medicare Part B to measure comorbidities and to identify patients who receive treatment in physicians' offices. Other research designs such as prospective cohort designs can be explored to assess the effect of dispensing channel on adherence among Medicare patients. 


\section{Limitations}

This study has several limitations to consider. First, because of the cross-sectional design, a causal link between dispensing channel use and adherence cannot be established. Second, our sample included both prevalent and incident users of specialty drugs, and patients' experience with their therapies may affect their medication adherence. However, this is only a limitation to the extent that the proportions of prevalent and incident users differ across dispensing channels and therapeutic classes. Third, adherence measured using prescription claims data does not guarantee the actual consumption of medications. However, use of pharmacy claims data to measure adherence has been documented previously. $6,7,16,29$

Fourth, we could not distinguish between nonadherence and physician-recommended therapy discontinuation. Fifth, the average follow-up period for adherence measurement was less than a year (327 days). Longer follow-up of patients would corroborate the relationship between dispensing channel use and adherence observed in this study. Sixth, Medicare Part D data do not provide information regarding severity of disease, clinical factors, behavioral and lifestyle factors, forgetfulness, and presence of social support, all of which may affect medication adherence. We could not control for these unobserved factors; however, they only affect our results to the extent that they differ across dispensing channels.

\section{Conclusions}

Nearly three quarters of Medicare patients received their selfadministered specialty drugs from retail as compared with only about $16 \%$ from the specialty channel. Medicare patients who used the specialty channel were more likely to be adherent to their specialty therapies compared with patients using the retail channel. However, this relationship varied by therapeutic class. Specialty channel use was associated with higher adherence rates among patients from the anticancer and TNFi classes but not for the DMT class.

\section{Authors}

HRISHIKESH P. KALE, MS, and NORMAN V. CARROLL, PhD, Virginia Commonwealth University School of Pharmacy, Richmond. ANISHA M. PATEL, PhD, Virginia Commonwealth University School of Pharmacy, Richmond, and Medtronic, Minneapolis, Minnesota.

AUTHOR CORRESPONDENCE: Hrishikesh Kale, MS, Virginia Commonwealth University School of Pharmacy, 1112 E. Clay St., McGuire Hall, Rm. 218, Richmond, VA 23298. Tel.: 917.515.2395;

E-mail:kaleh@vcu.edu.

\section{DISCLOSURES}

No funding supported this study. The authors reported no potential conflicts of interest.

Kale, Patel, and Carroll were responsible for study concept and design. Data analysis was conducted by Kale, assisted by Patel. The manuscript was written primarily by Kale, with assistance from Carroll.

Some findings from this study were presented during the poster presentation at the Academy of Managed Care Pharmacy Nexus held in National Harbor, Maryland, on October 4, 2016.

\section{REFERENCES}

1. Spatz I, McGee N. Health policy brief: specialty pharmaceuticals. Health Affairs. November 25, 2013. Available at: https://www.rwjf.org/content/dam/ farm/reports/issue_briefs/2013/rwjf409043. Accessed February 24, 2018.

2. Express Scripts. 2014 drug trend report. March 2015. Available at: http:// lab.express-scripts.com/lab/drug-trend-report/previous-reports. Accessed February 24, 2018.

3. Cramer JA, Roy A, Burrell A, et al. Medication compliance and persistence: terminology and definitions. Value Health. 2008;11(1):44-47.

4. Marin D, Bazeos A, Mahon FX, et al. Adherence is the critical factor for achieving molecular responses in patients with chronic myeloid leukemia who achieve complete cytogenetic responses on imatinib. J Clin Oncol. 2010;28(14):2381-88

5. Noens L, van Lierde MA, De Bock R, et al. Prevalence, determinants, and outcomes of nonadherence to imatinib therapy in patients with chronic myeloid leukemia: the ADAGIO study. Blood. 2009;113(22):5401-11.

6. Steinberg SC, Faris RJ, Chang CF, Chan A, Tankersley MA. Impact of adherence to interferons in the treatment of multiple sclerosis: a non-experimental, retrospective, cohort study. Clin Drug Investig. 2010;30(2):89-100.

7. Tan H, Cai Q, Agarwal S, Stephenson JJ, Kamat S. Impact of adherence to disease-modifying therapies on clinical and economic outcomes among patients with multiple sclerosis. Adv Ther. 2011;28(1):51-61.

8. Kane SV, Chao J, Mulani PM. Adherence to infliximab maintenance therapy and health care utilization and costs by Crohn's disease patients. Adv Ther. 2009;26(10):936-46.

9. Borah BJ, Huang X, Zarotsky V, Globe D. Trends in RA patients' adherence to subcutaneous anti-TNF therapies and costs. Curr Med Res Opin. 2009;25(6):1365-77.

10. Carter CT, Waters HC, Smith DB. Impact of infliximab adherence on Crohn's disease-related healthcare utilization and inpatient costs. Adv Ther. 2011;28(8):671-83.

11. Darkow T, Henk HJ, Thomas SK, et al. Treatment interruptions and nonadherence with imatinib and associated healthcare costs: a retrospective analysis among managed care patients with chronic myelogenous leukaemia. Pharmacoeconomics. 2007;25(6):481-96.

12. Brown MT, Bussell JK. Medication adherence: WHO cares? Mayo Clin Proc. 2011;86(4):304-14.

13. Yap AF, Thirumoorthy T, Kwan YH. Systematic review of the barriers affecting medication adherence in older adults. Geriatr Gerontol Int. 2016;16(10):1093-101

14. Suchanek D. The rise and role of specialty pharmacy. Biotechnol Healthc 2005;2(5):31-35

15. Iyengar R, Henderson R, Visaria J, Glave Frazee S. Dispensing channel and medication adherence: evidence across 3 therapy classes. Am J Manag Care. 2013;19(10):798-804 
16. Iyengar RN, Balagere DS, Henderson RR, LeFrancois AL, Rabbitt RM, Frazee SG. Association between dispensing channel and medication adherence among Medicare beneficiaries taking medications to treat diabetes, high blood pressure, or high blood cholesterol. J Manag Care Spec Pharm. 2014;20(8):851-61. Available at: https://www.jmcp.org/doi/10.18553/ jmcp.2014.20.8.851.

17. Iyengar RN, LeFrancois AL, Henderson RR, Rabbitt RM. Medication nonadherence among Medicare beneficiaries with comorbid chronic conditions: influence of pharmacy dispensing channel. J Manag Care Spec Pharm. 2016;22(5):550-60. Available at: https://www.jmcp.org/doi/10.18553/ jmcp.2016.22.5.550.

18. Fernandez EV, McDaniel JA, Carroll NV. Examination of the link between medication adherence and use of mail-order pharmacies in chronic disease states. J Manag Care Spec Pharm. 2016;22(11):1247-59. Available at: https://www.jmcp.org/doi/10.18553/jmcp.2016.22.11.1247.

19. Barlow J, Faris RJ, Wang W, et al. Impact of specialty pharmacy on treatment costs for rheumatoid arthritis. Am J Pharm Benefits. 2012;4(Special issue):SP49-56

20. Henderson RR, Visaria J, Bridges GG, Dorholt M, Levin RJ, Frazee SG. Impact of specialty pharmacy on telaprevir-containing 3-drug hepatitis $C$ regimen persistence. J Manag Care Spec Pharm. 2014;20(12):1227-34. Available at: https://www.jmcp.org/doi/10.18553/jmcp.2014.20.12.1227.

21. Stockl KM, Shin JS, Lew HC, et al. Outcomes of a rheumatoid arthritis disease therapy management program focusing on medication adherence. J Manag Care Pharm. 2010;16(8):593-604. Available at: https://www.jmcp. org/doi/abs/10.18553/jmcp.2010.16.8.593.
22. Tan H, Yu J, Tabby D, Devries A, Singer J. Clinical and economic impact of a specialty care management program among patients with multiple sclerosis: a cohort study. Mult Scler. 2010;16(8):956-63.

23. Tang J, Bailey J, Chang C, et al. Effects of specialty pharmacy care on health outcomes in multiple sclerosis. Am Health Drug Benefits. 2016;9(8):420-29.

24. Liu Y, Yang M, Chao J, Mulani PM. Greater refill adherence to adalimumab therapy for patients using specialty versus retail pharmacies. Adv Ther. 2010;27(8):523-32.

25. Tschida SJ, Aslam S, Lal LS, et al. Outcomes of a specialty pharmacy program for oral oncology medications. Am J Pharm Benefits. 2012;4(4):165-74.

26. ResDAC. Medicare Part D data. July 26, 2017. Available at: https://www. resdac.org/cms-data/search?f\%5B0\%5D=im_field_data_file_category\%3A56. Accessed February 24, 2018.

27. Centers for Medicare \& Medicaid Services. Medicare Part D specialty tier. Available at: https://www.cms.gov/Medicare/Prescription-DrugCoverage/PrescriptionDrugCovGenIn/Downloads/CY-2016-Specialty-TierMethodology.pdf. Updated 2015. Accessed February 24, 2018.

28. Tullman MJ. Overview of the epidemiology, diagnosis, and disease progression associated with multiple sclerosis. Am J Manag Care. 2013;19 (2 Suppl):S15-20.

29. Pladevall M, Williams LK, Potts LA, Divine G, Xi H, Lafata JE. Clinical outcomes and adherence to medications measured by claims data in patients with diabetes. Diabetes Care. 2004;27(12):2800-05. 


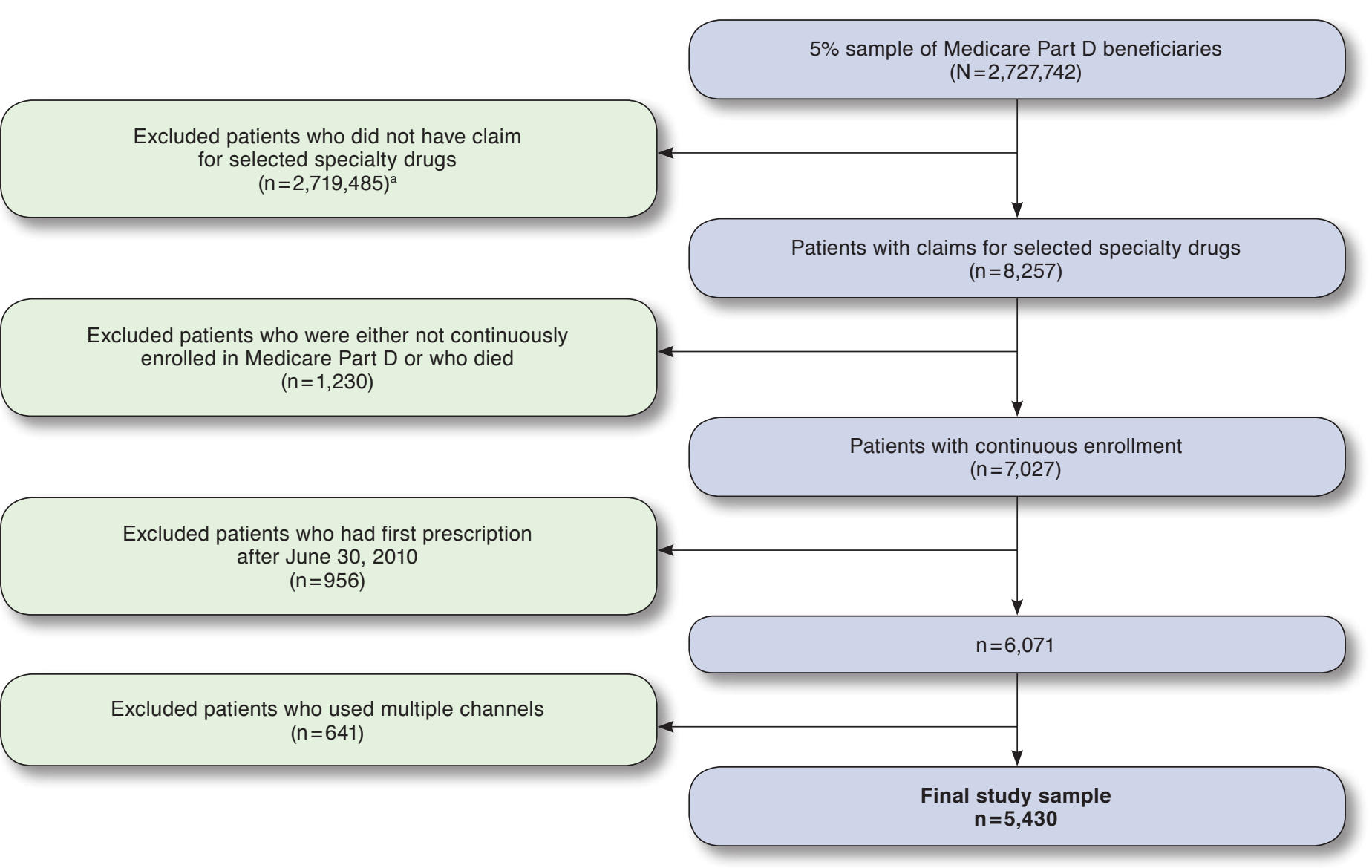

aTo identify specialty drugs, we calculated cost per 30 days supply for all the products and selected the top 300 products. Specialty drugs were defined as those with cost $\geq \$ 600$ per 30 days supply. Thirteen specialty drugs were identified from these 300 products. 


\section{A Comparison of Pharmacy Dispensing Channel Use and Adherence to Specialty Drugs Among Medicare Part D Beneficiaries}

\section{APPENDIX B Distribution of Specialty Drugs by Pharmacy Dispensing Channels}

\begin{tabular}{|c|c|c|c|c|c|c|c|c|c|c|}
\hline \multirow{2}{*}{$\begin{array}{l}\text { Class/Medications } \\
\text { Anticancer }(n=1,248)\end{array}$} & \multicolumn{2}{|c|}{ Retail, n (\%) } & \multicolumn{2}{|c|}{ Specialty, n (\%) } & \multicolumn{2}{|c|}{$\begin{array}{c}\text { Long-term Care, } \\
n(\%)\end{array}$} & \multicolumn{2}{|c|}{ Mail Order, n (\%) } & \multicolumn{2}{|c|}{ Other, $\mathrm{n}(\%)$} \\
\hline & 863 & (69) & 286 & (23) & 22 & (2) & 28 & (2) & 49 & (4) \\
\hline Dasatinib $(\mathrm{n}=34)$ & 27 & (79) & \multicolumn{2}{|c|}{ NR } & \multicolumn{2}{|c|}{ NR } & \multicolumn{2}{|c|}{ NR } & \multicolumn{2}{|c|}{ NR } \\
\hline Erlotinib $(n=211)$ & 156 & $(74)$ & 34 & $(16)$ & \multicolumn{2}{|c|}{ NR } & \multicolumn{2}{|c|}{ NR } & 12 & (6) \\
\hline Imatinib $(\mathrm{n}=381)$ & 294 & $(77)$ & 51 & (13) & \multicolumn{2}{|c|}{ NR } & 13 & (4) & 14 & (4) \\
\hline Lenalidomide $(\mathrm{n}=359)$ & 203 & (57) & 136 & (38) & \multicolumn{2}{|c|}{ NR } & \multicolumn{2}{|c|}{ NR } & \multicolumn{2}{|c|}{ NR } \\
\hline Sorafenib $(n=45)$ & 20 & (44) & 20 & (44) & $\mathrm{N}$ & & \multicolumn{2}{|c|}{ NR } & \multicolumn{2}{|c|}{ NR } \\
\hline Sunitinib $(n=46)$ & 35 & $(76)$ & \multicolumn{2}{|c|}{ NR } & \multicolumn{2}{|c|}{ NR } & \multicolumn{2}{|c|}{ NR } & \multicolumn{2}{|c|}{ NR } \\
\hline Thalidomide $(\mathrm{n}=119)$ & 90 & (76) & 22 & (18) & \multicolumn{2}{|c|}{ NR } & \multicolumn{2}{|c|}{ NR } & \multicolumn{2}{|c|}{ NR } \\
\hline$>1$ anticancer drugs $(n=53)$ & 38 & $(72)$ & 14 & (26) & \multicolumn{2}{|c|}{ NR } & \multicolumn{2}{|c|}{ NR } & \multicolumn{2}{|c|}{ NR } \\
\hline DMTs $(n=1,723)$ & 1,267 & $(74)$ & 212 & (12) & 138 & (8) & 70 & (4) & 36 & (2) \\
\hline Glatiramer acetate $(\mathrm{n}=832)$ & 642 & $(77)$ & 102 & (12) & 51 & (6) & 24 & (3) & 13 & (2) \\
\hline Interferon beta $1-\mathrm{a}(\mathrm{n}=350)$ & 246 & $(70)$ & 43 & (12) & 34 & (10) & 19 & (5) & & \\
\hline Interferon beta 1-a/albumin $(\mathrm{n}=251)$ & 183 & $(73)$ & 27 & (11) & 17 & (7) & 14 & (6) & & \\
\hline Interferon beta 1-b $(\mathrm{n}=222)$ & 141 & $(64)$ & 37 & $(17)$ & 28 & (13) & 12 & $(5)$ & & \\
\hline$>1$ DMTs $(\mathrm{n}=68)$ & 55 & (81) & \multicolumn{2}{|c|}{ NR } & \multicolumn{2}{|c|}{ NR } & \multicolumn{2}{|c|}{ NR } & \multicolumn{2}{|c|}{ NR } \\
\hline TNFi (n=2,459) & 1,893 & $(77)$ & 344 & (14) & 44 & (2) & 115 & (5) & 63 & (3) \\
\hline Adalimumab $(n=1,028)$ & 765 & $(74)$ & 172 & (17) & 18 & (2) & 50 & (5) & 23 & (2) \\
\hline Etanercept $(n=1,343)$ & 1,054 & $(78)$ & 163 & (12) & 24 & (2) & 65 & (5) & 37 & (3) \\
\hline$>1$ TNFi $(\mathrm{n}=88)$ & 74 & (84) & \multicolumn{2}{|c|}{ NR } & \multicolumn{2}{|c|}{ NR } & & & & \\
\hline
\end{tabular}

Note: Frequencies for cell counts $<11$ were not reported as per the data user agreement with Centers for Medicare $\&$ Medicaid Services.

$D M T=$ disease-modifying therapy; $N R=$ not reported; TNFi=tumor necrosis factor inhibitor. 